\title{
PENGARUH KODE ETIK KONSULTAN PAJAK TERHADAP KEPATUHAN WAJIB PAJAK YANG TERDAPAT PADA KKP MANSUR ARIF
}

\author{
Rima Sundari, Yosef Hans Christian \\ Program Studi Diploma IV Akuntansi Keuangan \\ Politeknik Pos Indonesia \\ rimasundari@poltekpos.ac.id, christianhans42@gmail.com
}

\begin{abstract}
Pajak adalah iuran wajib yang diberikan kepada warga suatu negara untuk menopang infratruktur suatu negara. Di Indonesia, masuk banyak warga yang belum sadar akan pentingnya membayar pajak, sehingga dapat diambil kesimpulan sementara bahwa kepatuhan wajib pajak di Indonesia masihlah sangat rendah. Oleh karena itu pemerintah mencari banyak solusi untuk menyelesaikan masalah ini, salah satunya adalah menggunakan jasa konsultan pajak untuk dapat membantu pemerintah dalam mensosialisasikan pentingnya membayar pajak, dan konsultan pajak itu sendiri membantu pemerintah dengan menerapkan kode etik yang berlaku di profesi konsultan pajak. Penelitian ini dilakukan untuk melihat pengaruh kode etik konsultan pajak terhadap kepatuhan wajib pajak ada kantor konsultan pajak Mansur Arif di Bandung. Jenis penelitian yang digunakan menggunakan penelitian kuantitatif dengan data primer.
\end{abstract}

\section{Kata Kunci: Kode Etik Konsultan Pajak, kepatuhan Wajib Pajak}

\begin{abstract}
Taxes are mandatory contributions given to citizens of a country to support the infrastructure of a country. In Indonesia, there are many citizens who are not aware of the importance of paying taxes, so it can be concluded for a while that taxpayer compliance in Indonesia is still very low. Therefore the government is looking for many solutions to solve this problem, one of which is to use the services of a tax consultant to be able to assist the government in disseminating the importance of paying taxes, and the tax consultant itself helps the government by implementing a code of ethics that applies in the tax consulting profession. This research was conducted to see the effect of the tax consultant code of ethics on taxpayer compliance in the Mansur Arif tax consulting office in Bandung. This type of research uses quantitative research with primary data.
\end{abstract}

\section{Keywords: Tax Consultant Code of Ethics, Taxpayer compliance}




\section{PENDAHULUAN}

Kepatuhan perpajakan merupakan masalah yang hampir dialami oleh semua negara yang menggunakan sistem perpajakan, baik itu pada negara berkembang maupun negara maju. Kepatuhan wajib pajak harus mendapatkan perhatian yang lebih bagi suatu negara, karena pajak memiliki peran yang besar terhadap sumber utama penerimaan negara.

Banyaknya wajib pajak di Indonesia yang masih tidak memahami pentingnya pajak untuk negara dan memilih untuk tidak membayarnya bukanlah hal baru, diambil dari (finance.detik.com, 2019)masih banyak masyarakat yang menolak untuk membayar pajak kepada negara degan berbagai alasan. Begitu juga dari, (economy.okezone.com, 2019)memaparkan bahwa kesadaran masyarakat dalam membayar pajak masihlah sangat minim, yang menyebabkan realisasi menjadi tidak maksimal, hal ini disebabkan karena masih tidak pahamnya masyarakat akan pentingnya pajak dan bagaimana cara membayarnya. Oleh karena itulah, pemerintah melakukan banyak tindakan untuk dapat mengatasi masalah tersebut, salah satunya adalah mengandalkan jasa konsultan pajak untuk turut membantu pemerintah dalam meningkatkan kesadaran membayar pajak dan membantu wajib pajak dalam melaksanakan kewajiban pajaknya. Dikutip dari, (Kompas.com, 2018)Direktorat Jenderal Pajak (DJP) Kementerian Keuangan menandatangani kerja sama dengan Ikatan Konsultan Pajak Indonesia (IKPI) dalam rangka memaksimalkan sosialisasi mengenai perpajakan terhadap masyarakat luas. Tujuan sosialisasi itu tidak lain adalah untuk meningkatkan penerimaan perpajakan serta membangun kesadaran di kalangan para wajib pajak (WP). Kerjasama ini terus berlanjut hingga saat ini,diambil dari, (antaranews.com, 2020)DJP masih terus menggunakan jasa konsultan pajak dan meminta mereka agar konsultan pajak publik dapat membina wajib pajak.

Penelitian mengenai pengaruh konsultan pajak terhadap kepatuhan wajib pajak sudah pernah dilakukan oleh peneliti terdahulu dan sekarang menjadi referensi dalam penelitian ini, diantaranya yaitu penelitian yang dilakukan oleh I Made Sudiartna (2018) yang berjudul Analisis Perilaku Konsultan Pajak untuk Meningkatkan Kepatuhan Wajib Pajak dan menghasilkan kesimpulan bahwa:

Berdasarkan hasil analisis data dan pemahasan yang telah dikemukakan oleh beliau di penelitiannya, ditemukan bahwa kode etik konsiltan pajak berpengaruh positif dalam kinerja konsultan pajak melayani klien yang mempengaruhi angka kesadaran pajak dalam emmenuhi kewajiban perpajakan, sedangkan profesionalisme dan sifat Machiavellian tida berpengaruh terhadap kepatuhan wajib pajak.

Sementara menurut (Khairannisa \& Charoline Cheisviyanny, 2019) dalam penelitiaanya yang berjudul Analisis Peranan Konsultan Pajak Terhadap Kepatuhan Wajib Pajak dalam Memenuhi Kewajiban Perpajakan (2019) menghasilkan simpulan bahwa:

- Alasan wajib pajak menggunakan jasa konsultan pajak terbagi atas tiga, yaitu kurangnya pengetahuan wajib pajak mengenai segala peraturan perpajakan, sistem perpajakan yang rumit serta alasan terakhir yaitu agar kewajiban perpajakan dapat dilaksanakan dengan efektif dan efisien.

- Tipe konsultan pajak yang banyak dipilih oleh wajib pajak badan yaitu tipe honest consultant karena wajib pajak menggunakan konsultan pajak bukan bertujuan untuk membantu mencari celah akan tetapi untuk membantu wajib pajak yang mengalami kesulitan untuk mengurus pajak sendiri.

- Saran konsultan pajak yang dipilih oleh semua wajib pajak yaitu saran konservatif, karena perusahaan tidak mau menanggung resiko jika menggunakan sanksi agresif. 
Berdasarkan latar belakang yang telah dipaparkan diatas, identifikasi masalah dalam penelitian ini, yaitu:

1. Bagaimana kode etik konsultan pajak pada KKP Mansur Arif?

2. Bagaimana kepatuhan wajib pajak pada KKP Mansur Arif?

3. Bagaimana pengaruh kode etik konsultan pajak terhadap kepatuhan wajib pajak pada KKP Mansur arif?

\section{KAJIAN PUSTAKA}

\section{Kode Etik Konsultan Pajak}

Mengacu ke PMK RI No. 111/PMK.03/2014 (PMK RI, 2014)tentang Konsultan Pajak Pasal 1, konsultan pajak adalah adalah orang yang memberikan jasa konsultasi perpajakan kepada Wajib Pajak dalam rangka melaksanakan hak dan memenuhi kewajiban perpajakannya sesuai dengan peraturan perundang-undangan perpajakan.

Menurut IKPI Bab I pasal 1, (IKPI, 2018)kode etik konsultan pajak adalah

(1) Kode Etik IKPI adalah kaidah moral yang menjadi pedoman dalam berfikir, bersikap dan bertindak bagi setiap anggota IKPI.

(2) Setiap anggota IKPI wajib menjaga citra martabat profesi dengan senantiasa berpegang pada Kode Etik IKPI.

(3) Kode Etik IKPI juga mengatur sanksi terhadap tidak dipenuhinya kewajiban atau dilanggarnya larangan oleh anggota IKPI.

Berdasarkan IKPI Bab II tentang Kepribadian Konsultan Pajak Indonesia pasal 2, (IKPI, 2018)konsultan pajak wajib:

1. Setia dan taat sepenuhnya kepada Pancasila dan Undang-Undang Dasar 1945;

2. Patuh pada hukum dan peraturan perpajakan, serta menjunjung tinggi integritas, martabat dan kehormatan profesi konsultan pajak;

3. Melakukan tugas profesi dengan penuh tanggung jawab, dedikasi tinggi dan independen;

4. Menjaga kerahasiaan dalam menjalankan profesi.

Isi dari Kode Etik IKPI mengenai hubungan dengan wajib pajak yaitu :

Kode etik IKPI pasal 7, (IKPI, 2018)Konsultan Pajak Indonesia wajib :

1. Menjunjung tinggi integritas, martabat dan kehormatan :

a. Dengan memelihara kepercayaan masyarakat;

b. Bersikap jujur dan berterus terang tanpa mengorbankan rahasia penerima jasa;

c. Dapat menerima kesalahan yang tidak disengaja dan perbedaan pendapat yang jujur, tetapi tidak boleh menerima kecurangan atau mengorbankan prinsip;

2. Bersikap professional :

a. Senantiasa menggunakan pertimbangan moral dalam pemberian jasa yang dilakukan;

b. Senantiasa bertindak dalam kerangka pelayanan dan menghormati kepercayaan masyarakat dan pemerintah; .

3. Menjaga kerahasiaan dalam hubungan dengan Wajib Pajak :

a. Harus menghormati dan menjaga kerahasiaan informasi yang diperoleh selama menjalankan jasanya, dan tidak menggunakan atau mengungkapkan informasi tersebut tanpa persetujuan, kecuali ada hak Kode Etik IKPI atau kewajiban legal profesional yang legal atau hukum atau atas perintah pengadilan untuk mengungkapkannya.

\section{Kepatuhan Wajib Pajak}

Mengacu kepada UU RI No. 16 tahun 2009 tentang KUP, pasal 17C tentang kepatuhan Wajib Pajak,(UU RI, 2009) dijelaskan bahwa: 
(1) Direktur Jenderal Pajak setelah melakukan penelitian atas permohonan pengembalian kelebihan pembayaran pajak dari Wajib Pajak dengan kriteria tertentu, menerbitkan Surat Keputusan Pengembalian Pendahuluan Kelebihan Pajak paling lama 3 (tiga) bulan sejak permohonan diterima secara lengkap untuk Pajak Penghasilan, dan paling lama 1 (satu) bulan sejak permohonan diterima secara lengkap untuk Pajak Pertambahan Nilai.

(2) Kriteria tertentu sebagaimana dimaksud pada ayat (1) meliputi:

a. tepat waktu dalam menyampaikan Surat Pemberitahuan;

b. tidak mempunyai tunggakan pajak untuk semua jenis pajak, kecuali tunggakan pajak yang telah memperoleh izin untuk mengangsur atau menunda pembayaran pajak;

c. Laporan Keuangan diaudit oleh Akuntan Publik atau lembaga pengawasan keuangan pemerintah dengan pendapat Wajar Tanpa Pengecualian selama 3 (tiga) tahun berturutturut; dan

d. tidak pernah dipidana karena melakukan tindak pidana di bidang perpajakan berdasarkan putusan pengadilan yang telah mempunyai kekuatan hukum tetap dalam jangka waktu 5 (lima) tahun terakhir.

\section{METODE PENELITIAN}

Penelitian ini merupakan penelitian jenis kuatitatif. (Sugiyono, 2019:16) menyatakan "Metode kuantitatif disebut sebagai metode positivistik karena berlandaskan pada filsafat positivisme. Metode ini disebut metode kuantitatif karena data penelitian berupa angkaangka dan analisis menggunakan statistik". Penelitian ini merupakan penelitian asosiatif dengan bentuk hubungan kausal. Menurut (Sugiyono, 2019:65-66), "Assosiatif adalah suatu rumusan masalah penelitian yang bersifat menanyakan hubungan antara dua variabel atau lebih. Terdapat tiga bentuk hubungan yaitu hubungan simetris, hubungan kausal, dan interaktifl resiprocal/ timbal balik". Sedangkan "Hubungan kausal adalah hubungan yang bersifat sebab akibat. Disini ada variabel independen (variabel yang mempengaruhi) dan dependen (dipengaruhi)".

Dalam penelitian ini, penulis menggunakan data primer sebagai sumber data, yaitu dengan pemberian kuesioner mengenai data yang dibutuhkan dalam penelitian secara langsung kepada responden.

Teknik sampling dalam penelitian ini adalah nonprobability sampling yang digunakan adalah sampling total. sampel dalam penelitian ini adalah wajib pajak badan yang menggunakan jasa kantor Konsultan Pajak Mansur Arif dengan total sebanyak 22 perusahaan yang tersebar di Indonesia.

\section{HASIL DAN PEMBAHASAN Uji Validitas}

Menurut (Sugiyono, 2017: 121) "Hasil penelitian yang valid bila terdapat kesamaan antara data yang terkumpul dengan data yang sesungguhnya terjadi pada obyek yang diteliti". Instrumen yang valid berarti alat ukur yang digunakan untuk mendapat data (mengukur) itu valid. Valid berarti instrumen tersebut dapat digunakan untuk mengukur apa yang seharusnya diukur. Untuk menguji validitas pada tiap-tiap item, yaitu dengan mengkorelasikan skor setiap butir dengan skor total. Kriteria yang dikatakan valid yaitu apabila rhitung $>$ rtabel . Jika rhitung $\leq$ rtabel, maka butir instrumen tersebut dinyatakan tidak valid

\section{Uji Reliabilitas}

Menurut (Sugiyono, 2017: 121) "Instrumen yang reliabel adalah instrumen yang bila digunakan beberapa kali untuk mengukur obyek yang sama, akan menghasilkan data yang sama". Reliabilitas menyangkut masalah ketepatan, keakuratan, dan konsistensi. Ketepatan ini dapat dinilai dengan analisis statistik untuk mengetahui kesalahan ukur. 
Pengujian reliabilitas dalam pengujian ini menggunakan SPSS. Metode yang digunakan adalah Cronbach's Alpha. Suatu variabel dikatakan reliabel jika memberikan nilai Cronbach's Alpha lebih besar dari nilai Cronbach's Alpha Standar $(0,6)$ dan apabila nilai Alpha $<0,60$ maka data dikatakan tidak reliabel.

\section{Uji Normalitas Data}

Menurut Sugiyono (2019:234) "Penggunaan statistic parametris mensyaratkan bahwa data setiap variabel yang akan dianalisis harus berdistibusi normal. Oleh karena itu sebelum pengujian hipotesis dilakukan, maka terlebih dulu akan dilakukan pengujian normalitas data"

Dengan kriteria sebagai berikut.

a. Jika signifikan $>0,05$ maka data distribusi normal.

b. Jika signifikan $<0,05$ maka data distribusi tidak normal.

Analisis Korelasi Spearman Rank

Menurut (Sugiyono, 2017: 245), "Kolerasi Spearman Rank adalah bekerja dengan data ordinal atau berjenjang atu ranking dan bebas distribusi."

Di dalam penelitian ini digunakan Uji korelasi spearman rank, untuk mengetahui tingkat hubungan variabel $\mathrm{X}$ dan variabel $\mathrm{Y}$. Untuk menentukan koefesienkorelasi, maka digunakan rumus berikut:

$$
\rho=1-\quad \begin{array}{ll}
6 \Sigma d_{i}^{2} \\
n\left(n^{2}-1\right)
\end{array}
$$

Keterangan:

\section{Gambar 3.1 Rumus Koefisien Korelasi Spearman Rank}

$\rho$ : koefisien korelasi spearman rank

$\mathrm{d}_{1}$ : selisih tiap pasang rank

$\mathrm{n}$ : banyaknya pasangan data

Untuk memberikan penafsiran terhadap koefisien korelasi yang ditemukan besar atau kecil, maka dapat berpedoman pada ketentuan berikut ini.

\section{Analisis Regresi Linear Sederhana}

Menurut (Sugiyono, 2017: 275), Analisis regresi linear sederhana adalah regresi yang hanya terdiri dari satu variabel dependen dan satu variabel independen. Regresi linear sederhana digunakan untuk mengetaui hubungan nilai satu variabel bebas dan satu varibel terikat melalui persamaan regresi

Persamaan regresi adalah:

$$
\mathrm{Y}=\mathrm{a}+\mathrm{bX}
$$

\section{Koefisien Determinasi}

\section{Gambar 3.2 Rumus Regresi Berganda}

Menurut (Sugiyono, 2017:231) "Koefisien determinasi digunakan untuk mencari pengaruh varians variabel dengan menggunakan teknik statistik. Koefisien determinasi dihitung dengan mengkuadratkan koefisien korelasi yang telah ditemukan, data selanjutnya dikalikan dengan $100 \%$.

Yang dinyatakan dalam persentase dengan rumus sebagai berikut:

$$
K d=r^{2}+100 \%
$$

\section{Gambar 3.3 Rumus Koefisien Determinasi}


Keterangan:

Kd: Koefisien Determinasi

$\mathrm{r}$ : Koefisien Korelasi

Dalam koefisien determinasi ini, nilai sisa dari presentasi $100 \%$ merupakan pengaruh faktor lain yang mempengaruhi variabel dependen $\mathrm{Y}$ sehingga koefisien determinasi ini tidak pernah negatif atau paling besar sama dengan satu dikarenakan nilai koefisien determinasi ini merupakan kuadrat dari koefisien korelasi. Pengaruh tinggi rendahnya koefisien determinasi tersebut digunakan pedoman adalah sebagai berikut:

Tabel 3.3

Pedoman Interpretasi Koefisien Determinasi

\begin{tabular}{|l|l|}
\hline Interval & Tingkat Pengaruh \\
\hline $0 \%-19,9 \%$ & Sangat Rendah \\
\hline $20 \%-39,9 \%$ & Rendah \\
\hline $40 \%-59,9 \%$ & Sedang \\
\hline $60 \%-79,9 \%$ & Kuat \\
\hline $80 \%-100 \%$ & Sangat Kuat \\
\hline
\end{tabular}

Menurut (Sugiyono, 2017: 230) menyatakan "Untuk menguji signifikansi hubungan, yaitu apakah hubungan yang ditemukan berlaku untuk seluruh populasi, maka perlu diuji signifikansinya". Untuk menguji tingkat signifikansi hubungan, dapat digunakan uji $\mathrm{T}$. Uji $\mathrm{T}$ dapat membandingkan $\mathrm{T}$ hitung dengan $\mathrm{T}$ tabel. Uji $\mathrm{T}$ dalam penelitian ini digunakan untuk mengetahui apakah variabel independen (Standar Akuntansi Pemerintahan (X1) dan Sistem Pengendalian Internal (X2)) secara parsial mempunyai pengaruh yang signifikan terhadap variabel dependen (Good Government Governance (Y)).

Uji T atau Uji Signifikansi Korelasi dirumuskan sebagai berikut:

Keterangan:

$$
t=\frac{r \sqrt{n-2}}{\sqrt{1-r^{2}}}
$$

$\mathrm{n}=$ jumlah data

$\mathrm{r}=$ koefisien korelasi

Kriteria penerimaan hipotesis menggunakan uji $\mathrm{T}$ adalah sebagai berikut:

a) Jika $t_{\text {hitung }} \geq t_{\text {tabel }}$ maka Ho ditolak dan Ha diterima. Artinya terdapat pengaruh yang signifikan antara variabel bebas terhadap variabel terikat

b) Jika $t_{\text {hitung }}<t_{\text {tabel }}$ maka Ho diterima dan Ha ditolak. Artinya tidak terdapat pengaruh yang signifikan antara variabel bebas terhadap variabel terikat.

Taraf signifikan yang digunakan adalah $5 \%(\alpha=0,05)$, yang secara umum digunakan dalam penelitian sosial. Untuk mengetahui pengaruh variabel independen terhadap variabel dependen, maka dilakukan uji hipotesis dengan menggunakan uji t dua pihak (two tailed) dan derajat kebebasan $(\mathrm{dk})=\mathrm{n}-\mathrm{k}-1$, dimana $\mathrm{k}$ merupakan jumlah variabel independen.

Adapun bentuk kurva dari uji dua pihak adalah sebagai berikut: 


\section{PEMBAHASAN}

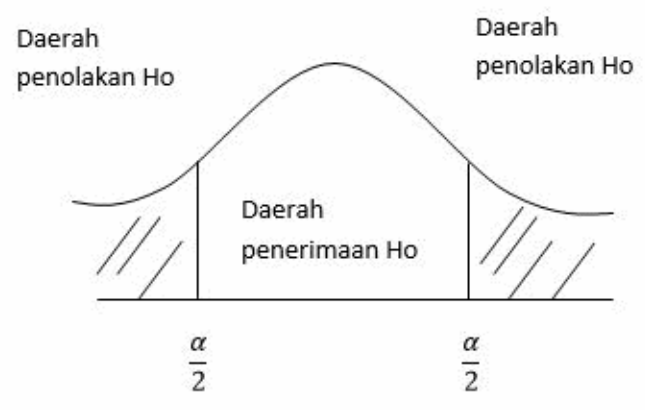

\section{Penerapan Kode Etik Konsultan Pajak di KKP Mansur Arif}

Kode etik konsultan pajak merupakan dasar bagi seorang konsultan pajak dalam bertindak dan menjalankan profesinya sebagai seorang konsultan pajak. Berdasarkan hasil penyebaran kuisioner kepada 22 responden, tanggapan dari responden yaitu pada jawaban sangat setuju 61,36\%, dari pilihan setuju sebesar 38,64\%, jawaban netral sebesar $0 \%$, menjawab tidak setuju sebesar $0 \%$, dan menjawab sangat tidak setuju sebesar $0 \%$, sehingga dapat dikatakan mayoritas responden setuju dengan pernyataan kode etik konsultan pajak. Dengan 9 pertanyaan yang telah diajukan dan mendapat skor dan dikategorikan.

Sehingga dapat disimpulkan bahwa penerapan kode etik konsultan pajak di KKP Mansur Arif telah dilaksanakan dengan baik. Dibuktikan dengan dalam menjalankan tugasnya KKP Mansur Arif telah menerapkan sesuai dengan kode etik IKPI yaitu integritas, profesionalisme, dan kerahasiaan.

\section{Kepatuhan Wajib Pajak pada KKP Mansur Arif}

Kepatuhan wajib pajak sangatlah dibutuhkan oleh negara agar pendapat negara dapat meningkat dan wajib pajak dapat sadar akan pentingnya membayar pajak. Berdasarkan hasil penyebaran kuisioner kepada 22 responden, tanggapan dari responden yaitu pada jawaban sangat setuju 35,35\%, dari pilihan setuju sebesar 37,88\%, jawaban netral sebesar $15,15 \%$, menjawab tidak setuju sebesar $1,52 \%$, dan menjawab sangat tidak setuju sebesar \%, sehingga dapat dikatakan mayoritas responden setuju dengan pernyataan kepatuhan wajib pajak. Dengan 4 pertanyaan yang telah diajukan dan mendapat skor dan dikategorikan.

Sehingga dapat disimpulkan bahwa kepatuhan wajib pajak di KKP Mansur Arif telah dilaksanakan dengan baik. Dibuktikan dengan dalam pelaksanaannya wajib pajak dianggap patuh apabila mengikuti kategori yang Mengacu kepada UU RI No. 16 tahun 2009 tentang KUP, pasal 17C tentang kepatuhan Wajib Pajak.

\section{Pengaruh Kode Etik Konsultan Pajak terhadap Kepatuhan Wajib Pajak pada KKP Mansur Arif}

Berdasarkan hasil penelitian dapat diketahui untuk menghitung atau mengukur hubungan antara variabel kode etik konsultan pajak (X) dan variabel kepatuhan wajib pajak (Y), digunakan pengujian korelasi. Hasil pengujian menunjukkan nilai korelasi Spearman Rank angka sebesar 0,324. Angka tersebut menunjukkan bahwa terjadi hubungan yang rendah, karena berada pada 0,20 - 0,399 yang artinya memiliki hubungan yang rendah antara kode etik konsultan pajak (X) dengan kepatuhan wajib pajak (Y).

Selanjutnya apakah kode etik konsultan pajak memiliki pengaruh atau tidaknya kepada kepatuhan wajib pajak, digunakan analisis regresi linier sederhana. Hasil pengujian menunjukkan perolehan nilai konstanta (a) sebesar 4.096 dan nilai koefisien 
regresi (b) sebesar 0.482 yang artinya jika nilai variabel kode etik konsultan pajak (X) bertambah 1, maka nilai variabel kepatuhan wajib pajak (Y) akan bertambah sebesar 0.482. Karena koefisien bernilai positif maka terjadi hubungan positif antara kode etik konsultan pajak terhadap kepatuhan wajib pajak, sehingga semakin baik kode etik konsultan pajak, maka kepatuhan wajib pajak akan semakin baik juga. Selanjutnya untuk melihat derajat kebebasan (dk) antara kode etik konsultan pajak (X) terhadap kepatuhan wajib pajak (Y) dapat digunakan analisis koefisien determinasi. Hasil analisis determinasi menujukkan bahwa ( $\mathrm{R}$ Square) sebesar 0,103 atau sebesar $10,3 \%$ menunjukkan persentase sumbangan pengaruh variabel independen (kode etik konsultan pajak) terhadap variabel dependen (kepatuhan wajib pajak) sebesar 10,3\%, sedangkan sisanya $89,7 \%$ dipengaruhi oleh variabel lain yang tidak termasuk dalam penelitian ini.

Pengujian selanjutnya yaitu uji t yang digunakan untuk mengetahui apakah variabel kode etik konsultan pajak (X) berpengaruh signifikan terhadap variabel kepatuhan wajib pajak (Y). Berdasarkan pengujian yang telah dilakukan, maka diperoleh hasil penelitian yang dimana hipotesis alternatif (Ha) ditolak. Artinya, hasil penelitian ini menunjukkan kode etik konsultan pajak tidak memiliki pengaruh yang signifikan terhadap kepatuhan wajib pajak pada KKP Mansur Arif.

Beberapa alasan yang mendasari bahwa kode etik konsultan pajak memang tidak memiliki pengaruh terhadap kepatuhan wajib pajak adalah, pertama apabila dilihat dari fenomena, dapat diliat bahwa pada tahun 2018 ketika IKPI sudah menjalin kerjasama dengan DJP pun ternyata tidaklah memberi pengaruh yang signifikan bahkan berdasarkan grafik kepatuhan pajak dari laporan SPT tahunan pun terlihat malah grafik pada tahun 2018 mengalami penurunan. Alasan kedua didapat dari tinjauan teori, dimana memang sedari awal, tidak ada satupu para ahli yang menyebutka ahwa definsi konsultan pajak adalah untuk mempengaruhi atau meningkatkan kepatuhan wajib pajak, mereka adalah orang yang bertugas melayani wajib pajak dalam menyelesaikan permasalahan perpajakannya. Begitupun apabila melihat dari isi kode etik konsultan pajak yang berlaku di Indonesia pun, tidak ada satupun tertulis bahwa konsultan pajak memiliki kewajiban meningkatkan kepatuhan wajib pajak di Indonesia. Alasan terakhir adalah apabila ditinjau dari lapangan langsung, sejak awal waib pajak pengguna jasa KKP Mansur Arif adalah WP yang datang sendiri untuk menyelesaikan urusan perpajakannya atas kemauannya sendiri dan sama sekali tidak ada campur tangan dari KKP Mansur Arif agar mereka mau datang dan menjadi patuh pajak.

\section{KESIMPULAN}

1. Berdasarkan hasil pengujian yang telah dilakukan diketahui bahwa pelaksanaan kode etik pada KKP Mansur Arif telah dilaksanakan sesuai dengan kode etik konsultan pajak yang berlaku di Indonesia yaitu dijalankan dengan integritas, profesionalise, dan kerahasiaan.

2. Berdasarkan hasil pengujian yang telah dilakukan diketahui bahwa kepatuhan wajib pajak pada KKP Mansur Arif telah berjalan sesuai dengan syarat kepatuhan seorang wajib pajak yang tercantum pada UU RI no. 16 tahun 2009 tentang KUP, pasal 17C tentang kepatuhan wajib pajak

3. Berdasarkan hasil pengujian yang telah dilakukan secara parsial tidak terdapat pengaruh yang signifikan antara Kode Etik Konsultan Pajak dengan Kepatuhan Wajib Pajak pada KKP Mansur Arif

\section{DAFTAR PUSTAKA}

Antaranews.com. (2020). DJP ingin konsultan pajak publik bina wajib pajak. Jumat, 14 Februari 2020 22:07 WIB. https://www.antaranews.com/berita/1298066/djp-ingin- 
konsultan-pajak-publik-bina-wajib-pajak

Aprianto, E. (2015). Etika profesi. In Etika Profesi Akuntansi (Vol. 1, Issue 1). Penerbit Andi.

Dan, H. N., \& Aliffioni, A. (2018). Analisis Efektivitas Penagihan Pajak Dengan Surat Paksa Dan Penyitaan Untuk Meningkatkan Penerimaan Pajak Pada Kantor Pelayanan Pajak Pratama Bekasi Utara. Jurnal Ilmiah Wahana Akuntansi, 13(2), $129-142$.

Economy.okezone.com. (2019). Kesadaran Bayar Pajak Masih Minim, Realisasi Belum Maksimal. Kamis 10 Oktober 2019 17:03 WIB.

https://economy.okezone.com/read/2019/10/10/20/2115301/kesadaran-bayar-pajakmasih-minim-realisasi-belum-maksimal

Finance.detik.com. (2019). Tolak Bayar Pajak Tak Berhak Pakai Layanan Publik. Rabu, 15 Mei 2019 21:05 WIB. https://finance.detik.com/berita-ekonomi-bisnis/d4551028/tolak-bayar-pajak-tak-berhak-pakai-layanan-publik

Ghozali, I. (2016). Aplikasi Analisis Multivariete Dengan Program IBM SPSS 23. Badan Penerbit Universitas Diponegoro.

IKPI. (2018). KODE ETIK IKPI.

Khairannisa, D., \& Charoline Cheisviyanny. (2019). Analisis Peranan Konsultan Pajak Terhadap Kepatuhan Wajib Pajak Dalam Memenuhi Kewajiban Perpajakan. Jurnal Eksplorasi Akuntansi, 1(3), 1151-1167.

http://jea.ppj.unp.ac.id/index.php/jea/article/view/133

Kompas.com. (2018). Tingkatkan Kesadaran Masyarakat, DJP Gandeng Konsultan Pajak. 28/02/2018, 17:06 WIB.

https://ekonomi.kompas.com/read/2018/02/28/170600426/tingkatkan-kesadaranmasyarakat-djp-gandeng-konsultan-pajak

Lunis, S. K. (2000). Etika Profesi Hukum. Penerbit LBJ.

Lusiana Sutanto dan Elisa Tjondro. (2013). PREFERENSI WAJIB PAJAK DALAM MEMILIH KONSULTAN PAJAK : HONEST CONSULTANT, CREATIVE CONSULTANT, DAN CAUTIOUS CONSULTANT Lusiana Sutanto dan Elisa Tjondro. 3(2), 201-214.

Mardiasmo. (2016). PERPAJAKAN. Penerbit Andi.

Pajak.go.id. (2019). Laporan Tahunan 2018 Direktorat Jenderal Pajak. Pajak.Go.Id. https://www.pajak.go.id/id/laporan-tahunan-2018

PMK RI. (2014). PMK RI No. 111/PMK.03/2014.

Pudyatmoko. (2018). HUKUM PAJAK. Penerbit Andi.

Rahayu, SE., M.Ak., Ak., C. (2016). Perpajakan: Konsep dan aspek Moral. Alfabeta.

Suandy. (2020). HUKUM PAJAK. Salemba Empat.

Subandi, H., \& Fadhil, M. I. I. (2018). Analisis Faktor-Faktor Yang Mempengaruhi Kepatuhan Pajak Bendahara Desa Di Kota Batu. Berkala Akuntansi Dan Keuangan Indonesia, 3(1), 1. https://doi.org/10.20473/baki.v3i1.5402

Sugiyono. (2017a). Metode Penelitian Bisnis. Alfabeta.

Sugiyono. (2017b). Metode Penelitian Kuantitatif, Kualitatif. Alfabeta.

Sujoko. (2015). Metode Penelitian Akuntansi. graha ilmu.

UU RI. (2003). Undang-Undang Nomor 20 Tahun 2003 Pasal 43.

UU RI. (2009). Undang-Undang No.16 Tahun 2009.

Waluyo. (2017). PERPAJAKAN INDONESIA. Salemba Empat.

Widodo, W. (2018). Moralitas Budaya, dan Kepatuhan Pajak. Erlangga. 